\title{
Growth Assessment of Broiler Chickens Given Bitter Leaves (Vernonia amygdalina) as Phyto-additive, Potentially Antimicrobial Agents of Lipids and Amino Acids
}

\author{
Jet Saartje Mandey ${ }^{* 1}$, Meity Sompie ${ }^{1}$ and Fenny Rinay Wolayan ${ }^{1}$ \\ ${ }^{1}$ Animal Husbandry Faculty, Sam Ratulangi University, Manado, North Sulawesi, Indonesia \\ *Corresponding Author.E-mail: jetsm fapet@yahoo.co.id
}

\begin{abstract}
This research was conducted to evaluate the growth of broiler chickens given bitter leaves (Vernonia amygdalina) in the drink as phytoadditive, potentially antimicrobial agents of lipids and amino acids. Amino acids of bitter leaves were analyzed by HPLC method, the fatty acid and fat content of bitter leaves were analyzed by A.O.A.C. Official Methods 2012. Antibacterial analysis of bitter leaves was prepared in three concentrations $(2.5 \%, 5 \%$ and $10 \%)$, and analyzed with disc diffusion method. A total of 200 D.O.C. broiler chicks were treated under a standard broiler management program until 7 days of age. The experiment was conducted as $4 \times 5$ completely randomized arrangement. The experiment lasted 28 days from. Bitter leaves juice was blended and given to broilers through drinking water in four kinds of treatment: $0,10,20$ and $30 \mathrm{ml} / \mathrm{L}$ drinking water. All chickens were fed diet contain $70 \%$ commercial feed, $27 \%$ broken corn and 3\% coconut oil and given ad libitum. Results showed that the bitter leaves contain high linolenic, linoleic and palmitic fatty acid, and phenylalanine, serine, isoleucine, glycine and arginine amino acids. Bitter leaves showed the power of antibacterial activity for S. aureus. Bitter leaves as feed additives in drinking water of broiler caused feed intake and carcass percentage were non significantly different. Final weight, WG, SGR, GE, FCR were highly significantly increased. Abdominal fat was highly significantly decreased, and there was no effect on the giblet. It can be concluded that bitter leaf can be used as phytoaddive in broiler diet.
\end{abstract}

Keywords: Antimicrobial, Bitter leaf, Broilers, Growth performance, Phytoadditive.

\section{INTRODUCTION}

The anti-microbial, anti-inflammatory, and antioxidative potential of herbal plants can affect poultry performance through improving digestive tract function. Herbs can also provide many functions in the poultry body system [1]. Antibiotic and antibacterial medications still used in poultry industry in several purposes that are therapeutic treatment, prevention or as traditional growth promoters [2]. Alternative phytogenic additives improve a number of principal processes in the livestock's body. They are also applicable in the food industry thanks to their antibacterial properties [3].

The biological activity of free fatty acids has an important role in the host's defense against pathogenic microorganisms, and, it plays a role in inhibiting bacterial growth. There are researches on the fatty acid derivatives and their antimicrobial activity [4]. Lauric, linoleic, palmitic, stearic, linolenic, myristic and oleic acids are fatty acids that have antibacterial and antifungal properties. Lauric acid is a saturated fatty acid with the most potential as a gram-positive antibacterial, while linoleic acid is an unsaturated fatty acid with the most potential as a gram-positive antibacterial. Oleic acid has potential antibacterial activity against S. aureus [5].

Antimicrobial peptide (AMP) a component of the plant defense system. Can be isolated from roots, seeds, flowers, stems, and leaves, and has activity against phytopathogens, as well as against pathogenic bacteria in humans [6]. Wang and Wang [7] and Hammami et al. [8] reported a study comparing the primary and tertiary structures of plant antimicrobial peptides showed that $33 \%$ of plant peptides had activity against bacteria, and these antibacterial peptides were composed of cysteine and/or glycine residues.

Plant AMP is considered a good drug because of its chemical properties combined with biological specificity 
such as antibodies [9]. AMP exhibits broad-spectrum antibiotic activity against pathogenic bacteria, fungi, enveloped viruses, and parasites [10]; [11]. The gastrointestinal microbial community has the ability to release low molecular weight peptides with antimicrobial properties capable of triggering an immune response [12]. AMP with broad-spectrum antimicrobial activity against gram-positive and gram-negative bacteria, and fungi, is an important defense barrier against pathogenic microorganisms [13].

Bitter leaves (Vernonia amygdalina Delile), is a small tree of Asteraceae family. It is called bitter leaf because of its abundant bitter taste [14]. V. amygdalina is drought tolerant although it grows better in humid environments [15]. It is used in tropical Africa for multiple purposes especially in culinary and traditional medicine for malaria, hepatitis, diarrhea, venereal disease, diabetes, digestive problems, skin disorders, coughs, constipation and in wounds treatments [16].

The administration of $V$. amygdalina up to $400 \mathrm{~g} / 150$ $\mathrm{kg}$ of feed affected the growth and measured hematological parameters, and prevented the occurrence of coccidiosis in broiler chickens. Bitter leaf can be used as an anticoccidial in broiler rations and does not interfere with the health status of poultry [17]. Giving bitter leaf increases gastro intestinal enzymes; hence, it could improve digestion and nutrients' assimilation. Inclusion $0.3 \%$ improved carcass quality parameters such as carcass weight, dressing percentage and has no deleterious effect on the internal organs of the birds and positively influenced the serum metabolites, thereby confirming that bitter leaf meal can reduce the risk factors of high cholesterol level [18]. The administration of 50 $\mathrm{mL} / \mathrm{L}$ of bitter leaf water extract in drinking water did not have an adverse effect on performance, reducing total cholesterol, LDL and glucose in broiler blood plasma [19].

Traditionally, much attention has been directed justifiably to the role of essential amino acids and fatty acids in animal nutrition. Fatty acids are in natural fats and dietary oils and are known to have antibacterial and antifungal activities. However, there is no information about the antibacterial activity of bitter leaves, and this study was to determine the fatty acids and amino acids of bitter leaves, as well as their potential antibacterial activity, and the effect of bitter leaf juice on the growth performance, carcass, and body fat level of broiler chickens.

\section{MATERIAL AND METHODS}

\subsection{Material}

Bitter leaves that were used for analizing of fatty acids and amino acids were dried, and powdered. For biological test, a total of 200 CP 707 broiler chicks were used, and bitter leaves juice were used as treatment. Bitter leaves were blended to make juice. At this stage, after washing, the bitter leaves are cut into small pieces with scissors. Then add water with a ratio of 1:10. Then the juice is made by crushing the leaves in a blender. Then stored in a refrigerator at a temperature of $4{ }^{\circ} \mathrm{C}$ to keep the bioactive compounds from the juice.

\subsection{Methods}

\subsubsection{General}

Phase I of the research was in laboratory, for analysing of fatty acids, amino acids, and antibacterial test. The fatty acid and fat content were analysis by A.O.A.C. Official Methods 2012. Amino acids were analyzed by HPLC method, used Thermo Ultimate 3000 RS Fluorescence Detector.

Antibacterial test was done by disc diffusion method [20]. S. aureus and E. coli as bacterial test. Bitter leaves powder was used in three solution concentrations of $2.5 \%, 5 \%$, and $10 \%$ using DMSO as solvent. Chloramphenicol $(0.1 \% / \mathrm{disc})$ was used as the positive reference standard, and antibacterial activity was observed by measuring the zone of inhibition, and all inhibition tests were performed in triplicate.

Phase II, research was carried out experiment in cage. The birds were treated under a standard broiler management program until $7 \mathrm{~d}$ of age. The birds were randomly distributed into 20 pens. The experiment was conducted as $4 \times 5$ completely randomized arrangement each of the 4 treatment groups with 5 replication, 10 birds per cage. The experiment lasted 28 days from 8 to $35 \mathrm{~d}$ of age. Bitter leaves juice then given to broilers through drinking water in several kinds of treatment: R0 $=$ drinking water without bitter leaves; $\mathrm{R} 1=10 \mathrm{ml}$ of bitter leaves juice $(\mathrm{BLJ}) /$ liter of drinking water, $\mathrm{R} 2=20 \mathrm{ml}$ of $\mathrm{BLJ} /$ liter of drinking water, and $\mathrm{R} 3=30 \mathrm{ml}$ of $\mathrm{BLJ} /$ liter of drinking water. Bitter leaves juice began to be given to chickens aged 8 days. All chickens were fed kibble contain $70 \%$ commercial diet, $27 \%$ corn, $3 \%$ coconut oil and given ad libitum. Consumption of drinking water and feed is calculated every day. On the $35^{\text {th }}$ day the chickens were weighed, then slaughtered, and the carcass weight was calculated after removing the feathers, head, legs and intestines. Gizzard, liver, heart and abdominal fat are weighed.

\subsubsection{Statistic}

The data were collected on body weight gain, feed intake and feed conversion ratio, carcass, edible organs and abdominal fat percentage, growth efficiency (GE) and specific growth rate (SGR \%). Data were subjected to one-way analysis of variance, and then the differences between the treatment means were compared using 
Duncan Multi Range Test. All statistical analysis was performed with IBM SPSS Statistics 24 software.

\section{RESULTS AND DISCUSSION}

The data of amino acids, fatty acids, and antibacterial activity of bitter leaves are shown in Table 1, Table 2 and Table 3. Result showed that bitter leaves contain amino acids phenylalanine, serine, isoleucine, glycine, arginine, valine, lysine, and fatty acids linolenic acid, linoleic acid, palmitic acid, cis-13,16-docosadienoic acid, oleic acid, stearic acid, lauric acid, palmitoleic acid, and fatty acid total was $38.55 \% \mathrm{w} / \mathrm{w}$, whereas fat content was $2.10 \%$ w/w.

Table 1. Dominant amino acids of bitter leaves

\begin{tabular}{|l|l|}
\hline Parameter & Bitter Leaves (ppm) \\
\hline Phenylalanine & 320.92 \\
\hline Serine & 297.91 \\
\hline Isoleucine & 138.65 \\
\hline Glycine & 136.85 \\
\hline Arginine & 111.43 \\
\hline Valine & 27.58 \\
\hline Lysine & 6.31 \\
\hline Parameter & Bitter Leaves (ppm) \\
\hline Phenylalanine & 320.92 \\
\hline Serine & 297.91 \\
\hline Isoleucine & 138.65 \\
\hline
\end{tabular}

Table 2. Dominant fatty acid of bitter leaves

\begin{tabular}{|l|c|}
\hline Parameter & Bitter Leaves $(\% \mathrm{w} / \mathrm{w})$ \\
\hline Fat Content & 2.10 \\
\hline Lauric acid & 0.46 \\
\hline Palmitic acid & 7.72 \\
\hline Palmitoleic acid & 0.43 \\
\hline Stearic acid & 0.71 \\
\hline Oleic acid & 0.93 \\
\hline Linoleic acid & 10.11 \\
\hline
\end{tabular}

Table 3. Dominant amino acids of bitter leaves

\begin{tabular}{|l|l|l|l|}
\hline \multirow{2}{*}{ Parameter } & \multirow{2}{*}{$\%$} & \multicolumn{2}{|c|}{ Inhibition zone (mm) } \\
\cline { 2 - 4 } & & E. coli & S. aereus \\
\hline \multirow{3}{*}{ Bitter Leaf } & 2.5 & 6.00 & 6.00 \\
\cline { 2 - 4 } & 5 & 6.00 & 7.76 \\
\cline { 2 - 4 } & 10 & 6.00 & 9.05 \\
\hline Chloramphenicol (C+) & 0.1 & 8.96 & 11.57 \\
\hline DMSO (C-) & & 0 & 0 \\
\hline
\end{tabular}

The method of giving bitter leaves juice through drinking water to broilers resulted in the same feed consumption, a highly significant increase in body weight, weight gain, feed conversion ratio, carcass weight, growth efficiency (GE), specific growth rate (SGR\%), significantly decreased in abdominal fat percentage $(47.46 \%)$, and have no effect in giblet (Table 4).

Zone of inhibition of bitter leaves for $E$. coli showed the same response for three concentration $(6 \mathrm{~mm})$, lower than the positive control $(8.96 \mathrm{~mm})$, and, for $S$. aureus at 5 and $10 \%$ concentration of bitter leaves $(9.05 \mathrm{~mm})$ was high enough but still under the positive control (11.57 $\mathrm{mm})$. Bitter leaves showed the highest value of inhibition zone at $10 \%$ concentration on $S$. aureus $(9.05 \mathrm{~mm})$; whereas the lowest inhibition zone was on E. coli (6 $\mathrm{mm})$. This showed that antibacterial in bitter leaf is effective against Gram positive bacteria at a concentration of $10 \%$ while is resistant against Gram negative. This study recommended the use of bitter leaf up to $10 \%$ concentration which is resistant to $E$ coli. For inhibition of $S$. aureus that the higher the concentration, the larger the diameter of the inhibition zone formed.

The antimicrobial property of fatty acids is closely related to the fatty acids' structure and their ability as antimicrobial agents. Saturated fatty acids with shorter chain lengths are more effective against microorganisms, while monounsaturated and polyunsaturated fatty acids are more effective against microorganisms at longer chain lengths. [21]. A report by Anzaku et al. [22] mentioned that free fatty acids (FFAs) with chain lengths C8 to C18 were more effective as antibacterial agents against Gram-positive bacteria than Gram-negative bacteria. Clavijo and Flo'rez [23] reported that for the nutrients to be digested, cooperation between biochemical functions and the microbiota in the digestive tract of chickens is required. It is necessary to select beneficial microbiota which involved in the production and health aspects; as well as in the protection from pathogens, detoxification processes, and modulation of the immune system.

$E$. coli inhabited the intestinal tract as well as the external environment. In both poultry and humans, E. coli present in the lower gastrointestinal tract [24]. Yoon et al. [5] reported that all Gram-positive test bacteria sp. are susceptible to administration of $0.01 \mathrm{mM}$ arachidonic acid. The time and concentration of S. aureus treatment affect the bactericidal activity of arachidonic acid. There was neither significant positive effect nor negative effect on broilers fed the various supplemental of bitter leaves [25]. This study was similar than that Osho et al. [26] reported that the bitter leaves extract $15 \mathrm{~g} / \mathrm{L}$ water increased feed conversion ratio of broilers without affecting haematological profile. Bitter leaves possess considerable amounts of proximates, minerals, vitamins. In this study, abdominal fat significantly reduced because of bitter leaves. Owens et al. [27] reported that the medicinal properties of bitter leaf have been attributed to 
Table 4. Effect of Bitter Leaves in drinking water on the growth performance

\begin{tabular}{|c|c|c|c|c|c|c|}
\hline \multirow{2}{*}{ Variables } & \multicolumn{4}{|c|}{ Treatments } & \multirow{2}{*}{ SEM } & \multirow{2}{*}{ pValue } \\
\hline & Ro & $\mathrm{R} 1$ & $\mathrm{R} 2$ & R3 & & \\
\hline Total FI (g/head) & 1844.30 & 1877.40 & 1867.60 & 1887.80 & 7.24 & .17 \\
\hline $\mathrm{FI}$ (g/head/day) & 87.82 & 89.40 & 88.93 & 89.89 & .345 & .17 \\
\hline Initial wt, g & 284.50 & 290.20 & 289.20 & 293.60 & 2.17 & .55 \\
\hline Final wt, $\mathrm{g}$ & $1243.40^{a}$ & $1362.20^{\mathrm{b}}$ & $1360.40^{\mathrm{b}}$ & $1477.20^{c}$ & 21.71 & .000 \\
\hline WG, $g$ & $965.00^{\mathrm{a}}$ & $1062.20^{\mathrm{b}}$ & $1065.0^{\mathrm{b}}$ & $1183.60^{c}$ & 20.32 & .000 \\
\hline SGR (\%) & $7.05^{a}$ & $7.33^{b}$ & $7.35^{b}$ & $7.69^{c}$ & .064 & .000 \\
\hline GE & $3.40^{a}$ & $3.66^{b}$ & $3.70^{b}$ & $4.03^{c}$ & .064 & .000 \\
\hline FCR & $1.91^{a}$ & $1.76^{b}$ & $1.76^{b}$ & $1.60^{c}$ & .29 & .000 \\
\hline Carcass wt, g & $912.60^{\mathrm{a}}$ & $987.20^{\mathrm{a}}$ & $990.80^{\mathrm{a}}$ & $1119.00^{\mathrm{b}}$ & 21.43 & .001 \\
\hline Carcass (\%) & 73.09 & 73.02 & 73.27 & 74.57 & 21.43 & .56 \\
\hline Liver (\%) & 2.98 & 2.47 & 2.89 & 2.57 & .12 & .36 \\
\hline Gizzard (\%) & 1.88 & 1.68 & 1.78 & 1.54 & .58 & .196 \\
\hline Heart $(\%)$ & 0.64 & 0.67 & 0.50 & 0.59 & .04 & .45 \\
\hline Abdominal Fat (\%) & $3.75^{a}$ & $3.08^{b}$ & $2.46^{c}$ & $1.97^{d}$ & .16 & .000 \\
\hline
\end{tabular}

$\mathrm{F} 1=$ feed intake; $\mathrm{WG}=$ weight gain; $\mathrm{SGR}=$ spesific growth rate; $\mathrm{GE}=$ growth efficiency

the biochemistry present in the plant. Certain chemicals from this plant have lipid-lowering properties, and that precise information about the proximate composition, phytochemical composition and micronutrients is the basis for understanding the mechanisms of this plant's anti-atherogenic potential.

\section{CONCLUSION}

Results showed that bitter leaves contain linoleic and palmitic fatty acid, and phenylalanine, serine, isoleucine, glycine and arginine amino acids in high percentage. Bitter leaves showed the power of antibacterial activity for $S$. aureus. Bitter leaves as feed additives in drinking water of broiler caused feed intake and carcass percentage were non significantly different. Final weight, WG, SGR, GE, FCR were highly significantly increased. Abdominal fat highly significantly decreased, and there were no effect on giblet. So, bitter leaf was recommended as feed additives alternative in broiler diet.

\section{AUTHORS' CONTRIBUTIONS}

First and second author designed the project; first, second and third author performed the experiments; first and second author prepared the article.

\section{ACKNOWLEDGMENTS}

The authors appreciate and thank to the LPPMUNSRAT for financial assistance of RTUU Project in this research.

\section{REFERENCES}

[1] F. Hernández, J. Madrid, V. García, J. Orengo, and M. D. Megías, "Influence of two plant extracts on broilers performance, digestibility, and digestive organ size," Poult. Sci., vol. 83, no. 2, pp. 169-174, 2004.

[2] M. S. Diarra and F. Malouin, "Antibiotics in Canadian poultry productions and anticipated alternatives," Front. Microbiol., vol. 5, no. JUN, pp. 1-15, 2014.

[3] K. Karásková, P. Suchý, and E. Straková, "Current use of phytogenic feed additives in animal nutrition: A review," Czech J. Anim. Sci. vol. 60, no. 12, pp. 521-530, 2015.

[4] S. Shukla et al., "Fatty acid composition and antibacterial potential of Cassia tora (leaves and stem) collected from different geographic areas of India," J. Food Drug Anal., vol. 26, no. 1, pp. 107-111, 2018.

[5] B. K. Yoon, J. A. Jackman, E. R. Valle-González, and N. J. Cho, Antibacterial free fatty acids and monoglycerides: Biological activities, experimental testing, and therapeutic applications, vol. 19, no. 4. 2018.

[6] R. Nawrot, J. Barylski, G. Nowicki, J. Broniarczyk, W. Buchwald, and A. GoździckaJózefiak, "Plant antimicrobial peptides," Folia Microbiol. (Praha)., vol. 59, no. 3, pp. 181-196, 2014.

[7] Z. Wang and G. Wang, "APD: The antimicrobial peptide database," Nucleic Acids Res., vol. 32, no. DATABASE ISS., pp. 590-592, 2004.

[8] R. Hammami, J. Ben Hamida, G. Vergoten, and I. 
Fliss, "PhytAMP: A database dedicated to antimicrobial plant peptides," Nucleic Acids Res., vol. 37, no. SUPPL. 1, pp. 963-968, 2009.

[9] T. B. Craik, D.J, Lee Meng-Han, Rehm F.B.H, "Ribosommaly-synthesised cyclic peptides from plants as drug leads and pharmaceutical scoffolds," Angew. Chemie Int. Ed. 6(11), 951952., pp. 5-24, 2018.

[10] B. Havenga, T. Ndlovu, T. Clements, B. Reyneke, M. Waso, and W. Khan, "Exploring the antimicrobial resistance profiles of WHO critical priority list bacterial strains," BMC Microbiol., vol. 19, no. 1, pp. 1-16, 2019.

[11] M. E. Marcocci et al., "The amphibian antimicrobial peptide temporin $b$ inhibits in vitro herpes simplex virus 1 infection," Antimicrob. Agents Chemother., vol. 62, no. 5, 2018.

[12] V. Singh et al., "Innate and specific gut-associated immunity and microbial interference," FEMS Immunol. Med. Microbiol., vol. 55, no. 1, pp. 612, 2009.

[13] J. Li, S. Hu, W. Jian, C. Xie, and X. Yang, "Plant antimicrobial peptides: structures, functions, and applications," Bot. Stud., vol. 62, no. 1, 2021.

[14] E. E. . Ekpo, A, Eseyin O. A, Ikpeme A.O, "Study of Some Biochemical Effect of Vernonia amygdalinain Rats.” 2007.

[15] Ikeh C.K, Ikeh P.E, and Ezike C.A, "Protective Potential of Aqueous Leaf Exract of Vernonia amygdalina in Cyclophosphamide - Induced Myelotoxicity," IOSR J. Pharm., vol. 04, no. 03, pp. 06-14, 2014.

[16] P. E. Ajebesone and J. O. Aina, "Potential African substitutes for hops in tropical beer brewing," Journal of Food Technology in Africa, vol. 9, no. 1. pp. 13-16, 2004.

[17] O. J. Banjoko, I. A. Adebayo., I. B. Osho, and M. D. Olumide, "Evaluation of varying levels of Vernonia amygdalina leaf meal on growth, hematological parameters and as anticoccidial," Int. J. Livest. Prod., vol. 10, no. 8, pp. 192-197, 2019.

[18] Daramola O.T, Oloruntola O.D, and Ayodele S.O, "Nutritional evaluation of bitter leaf meal ( Vernonia amygdalina ): effects on performance, carcass and serum metabolites of broiler chickens," Niger. J. Anim. Sci., vol. 20, no. 2, pp. 211-221-221, 2018.

[19] V. U. Oleforuh-Okoleh, S. O. Olorunleke, and I. J. Nte, "Comparative response of bitter leaf (Vernonia amygdalina) infusion administration on performance, haematology and serum biochemistry of broiler chicks," Asian J. Anim. Sci., vol. 9, no. 5, pp. 217-224, 2015.

[20] S. Pal, Y. K. Tak, and J. M. Song, "Does the antibacterial activity of silver nanoparticles depend on the shape of the nanoparticle? A study of the gram-negative bacterium Escherichia coli," Appl. Environ. Microbiol., vol. 73, no. 6, pp. 1712-1720, 2007.
[21] L. J. McGaw, A. K. Jäger, and J. Van Staden, "Antibacterial effects of fatty acids and related compounds from plants," South African J. Bot., vol. 68, no. 4, pp. 417-423, 2002.

[22] A. A. Anzaku, J. I. Akyala, A. Juliet, and E. C. Obianuju, "Antibacterial Activity of Lauric Acid on Some Selected Clinical Isolates," Ann. Clin. Lab. Res., vol. 05, no. 02, pp. 1-5, 2017.

[23] V. Clavijo and M. J. V. Flórez, "The gastrointestinal microbiome and its association with the control of pathogens in broiler chicken production: A review," Poult. Sci., vol. 97, no. 3 , pp. 1006-1021, 2018.

[24] A. L. Ballou et al., "Development of the chick microbiome: How early exposure influences future microbial diversity," Front. Vet. Sci., vol. 3, no. JAN, pp. 1-12, 2016.

[25] R. Mohammed, I., \& Zakariya, "Bitterleaf Addictive in Broiler Diets.Pdf," Reseacrh journal of animal. 2012.

[26] Osho I.B, Akindahusi A, Iqbasan F.A, and Adekunle D.J, "Effect orally administered bitter leaf (Vernonia amygdalina) extract on the growth performance and haematological parameters of broiler chicken," vol. 7, no. 4, pp. 117-121, 2015.

[27] O. Owen and A. Amakiri, "Lipid - lowering effects of bitter leaf (Vernonia amygdalina) in broiler chickens fed finishers' mash," Agric. Biol. J. North Am., vol. 2, no. 6, pp. 1038-1041, 2011. 